\title{
Xantoma plano difuso normolipêmico idiopático com hiperesplenismo
}

\section{Diffuse plane idiopathic normolipemic xanthoma with hiperesplenism}

\author{
Danielle Machado da Silva ${ }^{1}$ \\ Nayara de Castro Wiziack ${ }^{3}$ \\ Fernando Kenzo Hayashi ${ }^{5}$
}

\author{
Jorge João Chacha ${ }^{2}$ \\ Luiz Carlos Takita ${ }^{4}$
}

\begin{abstract}
Resumo: O xantoma plano difuso normolipêmico é doença rara, do grupo das histiocitoses, caracterizada pelo aparecimento de placas amareladas ou amarelo-alaranjadas, distribuídas simetricamente na pele e geralmente acompanhadas por xantelasma. Acomete principalmente adultos, podendo ou não apresentar alterações discretas dos lípides séricos. Relata-se o caso de uma paciente do sexo feminino, de 85 anos, há um ano com extensas placas amarelo-alaranjadas no tronco e abdome, assintomáticas. Os exames laboratoriais não demonstraram aumento dos lípides séricos, nem ocorrência de desordens retículo-endoteliais.

Palavras-chave: Mieloma múltiplo; Paraproteinemias; Xantomatose

Abstract: Diffuse plane normolipemic xanthoma is a rare disease, of a group of clinical syndromes called histiocytoses, characterized by the presence of yellowish or yellow-orange plaques, distributed symmetrically on the cutaneous surface and usually accompanied by xanthelasma. It affects mainly adults and it may cause discrete changes in serum lipids. The case of an 85-year-old female patient who has been showing extensive asymptomatic yellow-orange plaques in the trunk and abdomen for a year is reported. Laboratory tests did not show an increase in serum lipids or the occurrence of reticuloendothelial disorders.

Keywords: Multiple myeloma; Paraproteinemias; Xanthomatosis
\end{abstract}

\section{INTRODUÇÃO}

Os xantomas são lesões cutâneas de morfologia variável, decorrentes do depósito de lípides na pele. Esses depósitos processam-se no interior de histiócitos, que adquirem aspecto espumoso. São a exteriorização, na cútis, de doenças por distúrbio local ou geral do metabolismo lipídico ${ }^{1}$ e, em aproximadamente metade dos casos, ocorrem na ausência de hiperlipemia e hipercolesterolemia. ${ }^{2}$

O termo xantoma plano descreve morfologicamente um grupo de lesões xantomatosas que se manifestam na forma de máculas planas ou placas minimamente elevadas. ${ }^{3}$
Diferentes classificações de xantomas planos têm sido apresentadas e, em geral, diferenciam-se em dois grupos: 1) xantomas planos com aumento do nível sérico de lipídios; 2) xantomas planos com nível normal de lipídios séricos. Esse segundo grupo pode ainda ser dividido em três tipos: I) idiopáticos; II) associados a mieloma múltiplo, gamopatias monoclonais, e, menos frequentemente, a distúrbios linfoproliferativos; e III) associados a anormalidades de estrutura ou de conteúdo de lipoproteínas. ${ }^{4}$

Xantoma plano difuso (XPD) é um termo que tem sido usado para indicar lesões de pele mais

\footnotetext{
Aprovado pelo Conselho Editorial e aceito para publicação em 31.07.2009

* Trabalho realizado no Núcleo Hospital Universitário da Faculdade de Medicina (NHU/Famed) da Universidade Federal de Mato Grosso do Sul (UFMS) - Campo Grande (MS), Brasil.

Conflito de interesse: Nenhum / Conflict of interest: None

Suporte financeiro: Nenhum / Financial funding: None

Acadêmica do sexto ano do curso de medicina da Faculdade de Medicina (Famed) - Universidade Federal de Mato Grosso do Sul (UFMS) - Campo Grande (MS), Brasil.

Doutor em dermatologia pela Universidade de São Paulo (USP) e professor adjunto da Universidade Federal de Mato Grosso do Sul (UFMS) - Campo Grande (MS), Brasil.

Médica residente em dermatologia pela Famed - Universidade Federal de Mato Grosso do Sul (UFMS) - Campo Grande (MS), Brasil.

Doutorando em oncologia pela Universidade de São Paulo (USP), mestre em ciências da saúde pela Universidade de Brasília (UnB), professor adjunto de anatomia patológica especial da Faculdade de Medicina (Famed) - Universidade Federal de Mato Grosso do Sul (UFMS) - Campo Grande (MS), Brasil.

Acadêmico do terceiro ano do curso de medicina da Faculdade de Medicina (Famed) - Universidade Federal de Mato Grosso do Sul (UFMS) - Campo Grande (MS), Brasil.
}

(C)2010 by Anais Brasileiros de Dermatologia 
extensas e difusas que, usualmente, estão associadas ao tipo II da classificação dos xantomas planos. ${ }^{4}$

O XPD faz parte ainda das síndromes histiocíticas, que constituem grupo de doenças com apresentações clínicas que variam de formas localizadas e benignas a disseminadas e de mau prognóstico, e que desde 1987 são agrupadas em três categorias: as histiocitoses de células de Langerhans (HCL) ou classe I, as histiocitoses de fagócitos mononucleares (nãoLangerhans) ou classe II e as histiocitoses malignas ou classe III. ${ }^{5}$ O XPD pertence à classe II, de acordo com as características imunoistoquímicas que classificam as histiocitoses. ${ }^{6}$

\section{RELATO DO CASO}

Paciente do sexo feminino, de 85 anos, branca, procedente de Campo Grande -MS. Há um ano, notou o surgimento de manchas amareladas assintomáticas no tórax e abdome.

Ao exame dermatológico, apresentava placas planas, amarelo-alaranjadas, de bordas irregulares, bem delimitadas (Figura 1), de dimensões variadas, distribuídas na superfície cutânea de modo simétrico na região do tórax anterior e abdome (Figura 2), dorso (Figura 3) e nádegas. Face, região cervical, membranas mucosas, membros e regióes palmo-plantares foram poupados.

O exame anatomopatológico revelou, com a coloração de hematoxilina e eosina, epiderme com focos de espongiose e exocitose de linfomononucleares, e derme papilar evidenciando focos de infiltrado linfomononuclear com aglomerados de células xantomatosas de permeio (Figura 4) e ausência de sinais de malignidade. A imunoistoquímica mostrou positividade para o anticorpo CD68 (Figura 5) e negatividade para o marcador CD1a e a proteína S100.

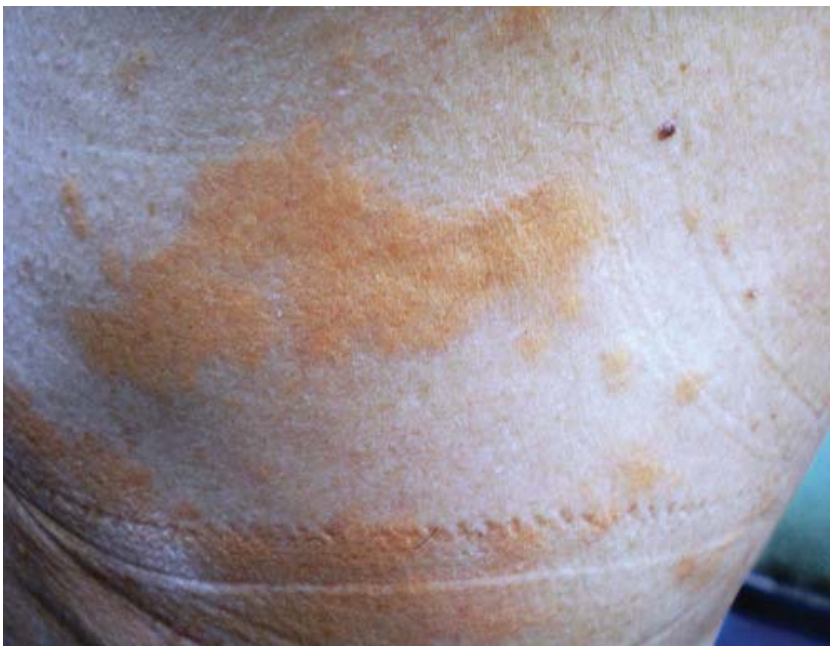

FIGURA 1: Placas planas amarelo-alaranjadas na região dorsal

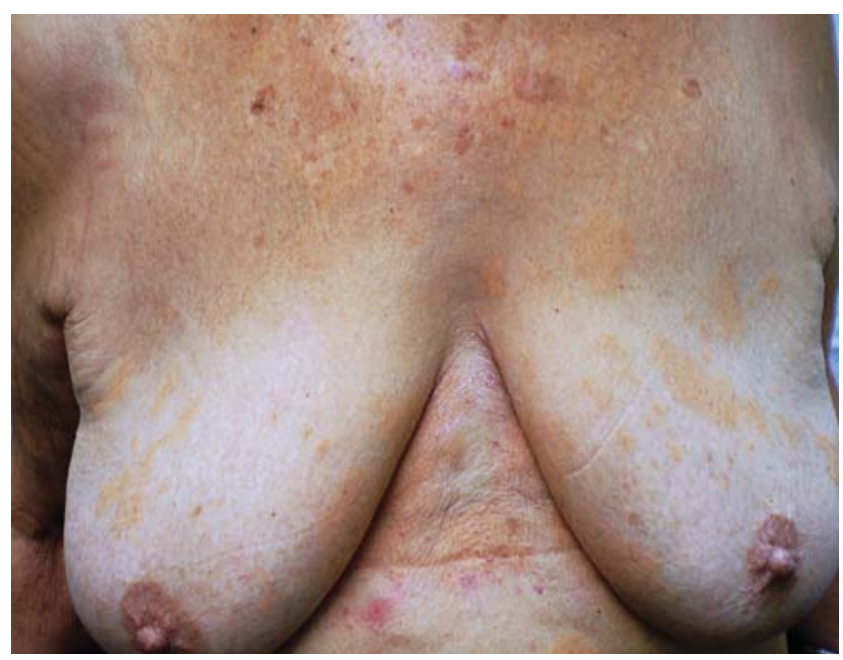

Figura 2: Placas no tórax anterior e abdome

Os seguintes exames complementares: glicemia, sódio, potássio, função hepática e renal, LDH, ferritina, proteínas totais e frações, fosfatase alcalina, gama-GT, bilirrubinas totais e frações, VHS, mucoproteínas, hormônios tireoidianos, eletroforese de proteínas séricas e na urina de 24 horas, imunoglobulina IgM, pesquisa de FAN, P-Anca e C-Anca, fator reumatoide, cardiolipina-anti IgG, cardiolipina-anti IgM, CH50, C3, C4, perfil lipídico (colesterol total, 130 $\mathrm{mg} / \mathrm{dl}$; LDL, 85,3 mg/dl; HDL, $28,1 \mathrm{mg} / \mathrm{dl}$; triglicerídeos, $83 \mathrm{mg} / \mathrm{dl}$ ) e a eletroforese de lipoproteínas (alfalipoproteínas, pré-beta-lipoproteínas, beta-lipoproteínas, quilomícrons) estavam dentro dos padrões de normalidade. Não foram encontradas proteinúria de Bence-Jones e crioglobulinas.

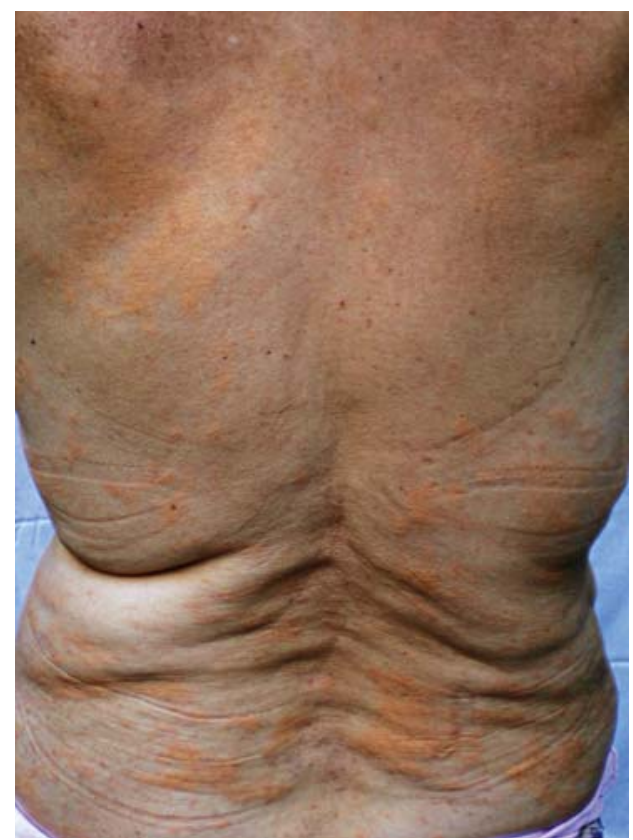

Figura 3:

Extensão das lesões, atingindo dorso 

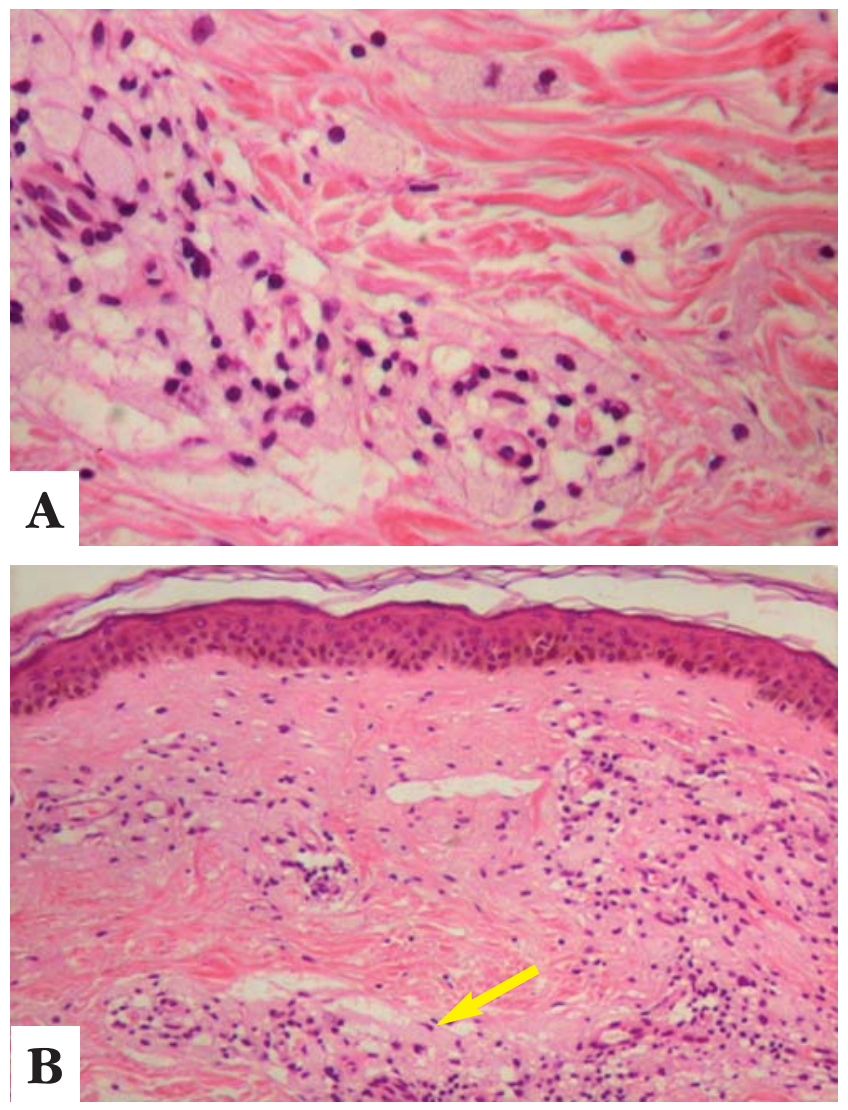

FIgURA 4: Exame histopatológico da região abdominal: A. aglomerados de células xantomatosas com infiltrado de linfomononucleares; $\mathrm{B}$. focos de células espumosas na derme (seta amarela). (HE, 200x e 100x)

As sorologias para hepatites B e C e leishmaniose foram negativas. As radiografias de tórax, de crânio e de pelve mostraram-se sem alterações. $\mathrm{O}$ aspirado de medula óssea revelou ausência de parasitas e de infiltração por células com características neoplásicas.

O hemograma constatou pancitopenia: eritrócitos, 3,63 milhões $/ \mathrm{mm}^{3}$; leucócitos, $2.640 / \mathrm{mm}^{3}$; plaquetas, $93.000 / \mathrm{mm}^{3}$. A ultrassonografia abdominal indicou esplenomegalia discreta.

\section{DISCUSSÃO}

O xantoma plano difuso normolipêmico é entidade clínico-patológica bem definida, ${ }^{7}$ que acomete principalmente adultos de ambos os sexos e se caracteriza pelo desenvolvimento de máculas e placas planas ou levemente elevadas de coloração amarelada, amarelo-acastanhada ${ }^{8}$ ou amarelo-alaranjada, ${ }^{7}$ que variam muito em dimensão e podem aparecer nitidamente demarcadas ou com bordas pouco delimitadas e, usualmente, com distribuição simétrica na superfície corporal. ${ }^{3}$

A manifestação das lesões ocorre, preferencialmente, na porção superior do tronco, nas faces laterais da região cervical e nos membros; ${ }^{3}$ porém, qual-

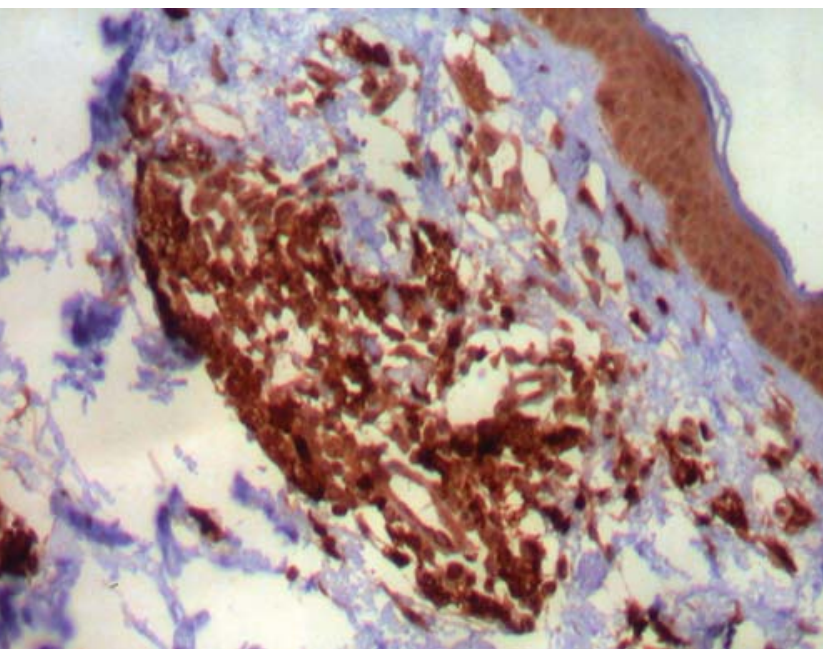

Figura 5: Imunoistoquímica revelando positividade para o anticorpo CD68 (200x)

quer parte do corpo, ${ }^{7,8}$ como flexuras, ${ }^{7}$ abdome ${ }^{9} \mathrm{e}$ nádegas, ${ }^{10}$ pode apresentar a lesão, que geralmente é acompanhada ou precedida por xantelasma. ${ }^{3}$

O xantoma plano difuso normolipêmico foi descrito pela primeira vez em 1962 por Altman e Winkelmann, ${ }^{11}$ os quais inicialmente acreditavam que as lesões cutâneas não eram associadas a distúrbios internos. Entretanto, quatro anos mais tarde, Lynch e Winkelmann ${ }^{3}$ confirmaram a associação dessas lesões a desordens do sistema retículo-endotelial, principalmente o mieloma múltipo. Outros relatos mostraram ainda a associação da afecção a gamopatias monoclonais, ${ }^{4,7,9}$ além de distúrbios linfoproliferativos. ${ }^{2,3,10}$

$\mathrm{Na}$ análise histopatológica, células espumosas macrófagos com gotículas lipídicas engolfadas - e número variável de células gigantes de Touton, linfócitos e histiócitos espumosos podem ser vistos na derme superior e, ocasionalmente, podem ter localização perivascular. ${ }^{10,12}$ Além disso, necrobiose focal tem sido observada no XPD, e a progressão deste para xantogranuloma necrobiótico tem sido relatada, sugerindo que ambos possam representar duas condições clínicas de um mesmo espectro de doenças. ${ }^{10}$

No caso ora observado, a distribuição das lesões não demonstrou o padrão tipicamente encontrado, uma vez que elas acometeram tórax anterior, abdome, dorso e nádegas, sem presença de xantelasma. Também não foi observada até o momento, contrariando a tendência, a associação do XPD a alterações sistêmicas, principalmente a distúrbios mieloproliferativos. $\mathrm{O}$ que se verificou foi apenas hiperesplenismo isolado, justificando a pancitopenia. E devido à frequente ocorrência de leishmaniose visceral na região, procurou-se descartar sua possível presença.

O exame histopatológico sugeriu o diagnóstico de xantoma plano difuso. Uma vez que não mostrou 
necrobiose e nem a ocorrência de infiltrado granulomatoso na derme e tecido subcutâneo,$^{13}$ descartamos, principalmente em associação com a clínica, xantogranuloma necrobiótico. A imunoistoquímica confirmou histiocitose de fagócitos mononucleares. ${ }^{6}$

A patogênese do XPD não está claramente definida. No caso da associação a gamopatias, alguns autores acreditam que complexos paraproteínas-lipoproteínas são depositados na pele. ${ }^{14}$ Outros sugerem a infiltração de células leucêmicas na pele com subsequente xantomização. ${ }^{15}$ Outros, ainda, consideram o XPD uma forma de histiocitose não-Langerhans. ${ }^{6}$

Uma hipótese para explicar a ocorrência de xantoma em pacientes normolipêmicos é a de que a formação de complexos histiócitos-monócitos, funcionalmente anormais, estimularia hiperplasia e xantomização secundária, ${ }^{2}$ o que indica a provável patogênese do presente caso.

\section{REFERÊNCIAS:}

1. Sampaio SAP, Rivitti EA. Dermatologia. 3 ed. São Paulo: Artes Médicas; 2007. p.910-9.

2. Maxit MJ, Paz RA. Xantoma plano difuso com artritis, serosits, eritema nodoso, vasculitis y leucemia mielomonocitica. Medicina (B Aires). 2001;61:187-90.

3. Lynch PJ, Winkelmann RK. Generalized plane xanthoma and systemic disease. Arch Dermatol. 1966;93:639-46.

4. Daoud MS, Lust JA, Kyle RA, Pittelkow MR. Monoclonal gammopathies and associated skin disorders. J Am Acad Dermatol. 1999; 40:507-35.

5. Quattrino AL, Silveira JCG, Diniz C, Briggs MC, Vilar E. Histiocitose de células de Langerhans: relato de caso e revisão da literatura. An Bras Dermatol. 2007;82:337-41.

6. Luz FB, Gaspar AP, Gaspar NK, Silva MR. Os histiócitos e as histiocitoses não Langerhans em dermatologia. An Bras Dermatol. 2003;78:99-118.

7. Buezo GF, Porras JI, Fraga J, Sanchez E, Aragües M, Daudén E. Coexistence of diffuse plane normolipaemic xanthoma and amyloidosis in a patient with monoclonal gammopathy. $\mathrm{Br} \mathrm{J}$ Dermatol. 1996;135:460-2.

8. Akhyani M, Daneshpazhooh M, Seirafi H, Naraghi ZS. Diffuse plane xanthoma in an otherwise healthy woman. Clin Exp Dermatol. 2001;26:405-7.

9. Ginarte M, Peteiro C, Toribio J. Generalized plane xanthoma and idiopathic Bence-Jones proteinuria. Clin Exp Dermatol. 1997;22:192-4.

10. Marcoval J, Moreno A, Bordas X, Gallardo F, Peyrí J. Diffuse plane xanthoma: Clinicopathologic study of 8 cases. J Am Acad Dermatol. 1998;39:439-42.
De acordo com alguns autores, somente uma minoria dos casos é considerada idiopática. Contudo, a frequência dos relatos com doença associada pode ser explicada pela tendência dos autores em descrevêlos, preterindo os casos idiopáticos. ${ }^{10}$

Como a paciente não apresentou nenhum critério para diagnóstico de mieloma múltiplo, nem os exames complementares revelaram gamopatias monoclonais ou distúrbios linfoproliferativos, classifica-se o caso como xantoma plano difuso normolipêmico idiopático.

Uma vez que xantomas podem manifestar-se vários anos antes do aparecimento de desordens sistêmicas ou distúrbios hematológicos, recomenda-se acompanhamento e seguimento dos pacientes em que esse diagnóstico tenha sido estabelecido.

11. Altman J, Winkelmann RK. Diffuse normolipemic plane xanthoma. Generalized xanthelasma. Arch Dermatol. 1962;85:633-40.

12. Bragg J. Diffuse plane xanthomata. Dermatol Online J. 2005;11:4.

13. Macedo DM, Hirata SH, Michalany NS, Enokihara MMSS, Enokihara MY. Xantogranuloma necrobiótico solitário sem paraproteinemia. An Bras Dermatol. 2008;83:243-6.

14. Taylor JS, Lewis LA, Battle JD, Butkus A, Robertson AL, Deodhar S, et al. Plane xanthoma and multiple myeloma with lipoprotein-paraprotein complexing. Arch Dermatol. 1978;114:425-31.

15. Vail JT Jr, Adler KR, Rothenberg J. Cutaneous xanthomas associated with chronic myelomonocytic leukemia. Arch Dermatol. 1985;121:1318-20.

\author{
ENDEREÇO PARA CORRESPONDÊNCIA / MAILING ADDRESS: \\ Danielle Machado da Silva \\ Rua Tenente Waldivino 188, Bl B-6, ap. 11, Vila Célia \\ 79020090 Campo Grande MS \\ Tel.:/Fax: 67964759516732136086 \\ E-mail:dmsms@botmail.com
}

Como citar este artigo/How to cite this article: Silva DM, Chacha JJ, Wiziack NC, Takita LC, Hayashi FK. Xantoma plano difuso normolipêmico idiopático com hiperesplenismo. An Bras Dermatol. 2010;85(1):73-6. 